\title{
Harmonical oscillator and electro-mechanical analogy: an interdiscinary experiment to high precision mass variation measurements
}

\author{
Ailton M. Watanabe ${ }^{1,2}$, Adriano dos Santos ${ }^{2}$ e Paulo R. Bueno ${ }^{* 1,2}$ \\ ${ }^{1}$ USP, Faculdade de Filosofia, Ciências e Letras de Ribeirão Preto, \\ Departamento de Física e Matemática, CEP 14040-901, Ribeirão Preto, SP, Brasil \\ ${ }^{2}$ UNESP, Universidade Estadual Paulista, Instituto de Química, Departamento de Físico-Química, \\ P. O. Box 355, CEP 14800-900, Araraquara, SP, Brasil. \\ *autor correspondente: prbueno@iq.unesp.br
}

\begin{abstract}
In general, the traditional Physics courses needs examples of the aplications of the Physics concepts in other areas such as Chemistry and Biology. This lacks tend to demotivate Chemistry and Biology students regarding to deal with Physical concepts developed in classroom. In this work, the analogy among mechanic and electric oscillators is investigated to be applied in Chemistry and Biology areas, showing to be valuable due to its aplication in techniques that aims to measure mass variation with high precision. This measure could be made in a direct or indirect way. These techniques are known as electrogravimetric techniques and they are important in biosensor aplications. Thus, this paper explores the electromechanic analogy in an interdisciplinary way involving areas like Physics, Chemistry and Biology. Based on this analogy, it is proposed an experiment that can be applied in different ways, i.e. by an basic approach or more deeper, depending on the students specific formation, in other words, Physics, Chemistry or Biology.
\end{abstract}

Keywords: Block-spring oscillator; RLC oscillator; eletromechanical analogy; piezoelectric oscillator; electrogravimetry.

\section{Introdução}

O oscilador harmônico simples é abordado tanto em cursos de física básica [1-3] quanto em cursos de física avançada $[4,5]$. Como exemplos de osciladores harmônicos simples, citam-se o pêndulo e um sistema massa-mola, ambos como sistemas ideais ou conservativos, ou seja, onde não se considera forças dissipativas. No exemplo do oscilador massa-mola ideal a energia total do sistema varia entre a energia potencial elástica, originada da deformação da mola, e a energia cinética, devido ao movimento do bloco. No exemplo do pêndulo ideal a energia total do sis- tema varia entre a energia potencial gravitacional e energia cinética da esfera. Além dos osciladores harmônicos, são estudados os osciladores amortecidos, tais como o sistema massa-mola vertical com uma superfície submersa em um fluido [4, 6] ou um pêndulo composto de um fio longo e uma esfera de pequena densidade em atrito com o ar. São estudados também os osciladores forçados (oscilador harmônico submetido a uma força externa) e forçado amortecido (movimento de uma agulha magnética [7]).

Os osciladores citados anteriormente são exemplos de osciladores harmônicos do tipo mecânicos. Além destes, existem os osciladores ele- 
tromagnéticos, ou seja, circuitos elétricos que envolvem indutores $(L)$ e capacitores $(C)$, podendo ou não apresentar um elemento resistivo $(R)$. Nesses sistemas ideais somente elementos indutivos e capacitivos estão presentes. Esses circuitos formados por estes dois elementos são chamados de circuitos $L C$. Portanto, um circuito $L C$ é exemplo de oscilador harmônico sem dissipação, no qual a energia do sistema oscila entre elétrica (devido ao capacitor) e magnética (devido ao indutor). Por outro lado, um circuito $R L C$ é um exemplo de oscilador amortecido, devido ao fato que o elemento resistivo dissipa energia na forma de calor para o ambiente externo. Quando nesse circuito é adicionada uma fonte de energia externa como uma diferença de potencial alternada (gerador), esse oscilador torna-se um exemplo de oscilador forçado ou forçado amortecido [8], porque se mantém oscilando desde que a energia fornecida pelo gerador seja maior que aquela dissipada pelo resistor $(R)$ por ciclo.

Devido às semelhanças matemáticas que descrevem o comportamento oscilatório dos sistemas mecânico e eletromagnético, é possível fazer uma analogia quantitativa direta entre eles. Esta analogia é conhecida como equivalência eletromecânica.

Embora esses exemplos de osciladores mencionados assim como a equivalência eletromecânica sejam muito bem estudados e discutidos nos livros didáticos, ainda há uma deficiência no contexto prático, sobretudo na visualização deste conteúdo em aplicações tecnológicas e no desenvolvimento científico. Além do mais, diversas disciplinas oferecidas tanto nos cursos de graduação em física quanto nos de química e biologia não exploram a interdisciplinaridade inerentes destas ciências, que poderiam ser utilizadas como forças motivadoras ao aprendizado, sobretudo mostrando ao aluno de graduação as potenciais aplicações dos conceitos relacionados à essas áreas, bem como no desenvolvimento de pesquisas em nível de pós-graduação das quais abrangem.

Desta forma, com o intuito de enriquecer a literatura com exemplos de experimentos que sejam capazes de explicar a analogia eletromecânica e mostrar a interdisciplinaridade entre as áreas de biologia, química e física, o objetivo deste trabalho é descrever esta analogia e mostrar como apli- cá-la em estudos de técnicas eletrogravimétricas, ou seja, técnicas baseadas na detecção de massa através de um sinal elétrico. Estas técnicas são ferramentas importantes na elucidação da formação de monocamadas automontadas (SAM, do inglês Self Assembled Monolayer) de determinadas moléculas orgânicas contendo grupos específicos sobre um substrato metálico, assim como no estudo e desenvolvimento de biossensores [9-11] atualmente muito explorados para estudo científico na área de biotecnologia, nos quais os conceitos de oscilador harmônico e equivalência eletromecânica encontram-se presentes.

\section{Teoria e Aplicação}

O conteúdo teórico que permite a interpretação da analogia dos sistemas mecânico e elétrico é de fundamental importância no entendimento de sua aplicação em dispositivos sensores de massa e, por isso, merece uma abordagem detalhada.

Um oscilador massa-mola em repouso sobre uma superfície perfeitamente lisa (Figura 1(a)), possui energias cinética $\left(E_{C}\right)$ e potencial elástica $\left(E_{P}\right)$ nulas, uma vez que o bloco não está em movimento e a mola não se encontra deformada. Ao se deslocar o bloco de sua posição de repouso para uma posição $+X$ (Figura 1(b)), a energia utilizada para promover o movimento do bloco (bioquímica, mecânica, etc.) foi armazenada no sistema como energia potencial elástica. Esta energia está associada ao trabalho $W$ realizado para deformar a mola, dado pela integral:

$$
W=\int_{0}^{X} F d x
$$

A força envolvida é a força restauradora da mola, contrária ao movimento. Segundo a lei de Hooke:

$$
F=-k x
$$

Sendo $k$ a constante de mola e $x$ a deformação. 
Substituindo a Equação 2 na Equação 1 e resolvendo a integral, encontra-se:

$$
W=-\frac{1}{2} k X^{2}
$$

Sabe-se que variação de energia potencial do sistema é definida com sendo igual ao oposto do trabalho realizado pela força restauradora da mola:

$$
\Delta E_{P}=-W
$$

Como inicialmente a energia potencial é nula (a mola estava em seu estado natural) a energia potencial do sistema é:

$$
E_{P}=-W=\frac{1}{2} k X^{2}
$$

Portando, a energia total do sistema é dada pela relação da Equação 5, que depende da constante $k$ de deformação da mola e o quanto esta foi deformada, ou seja, do valor de $X$.

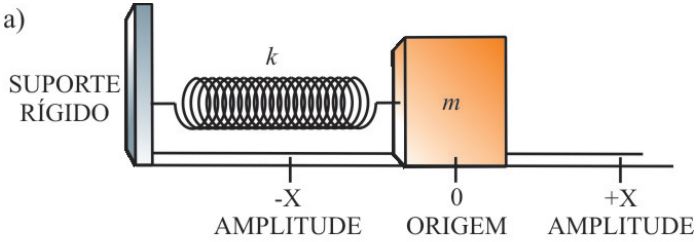

b)

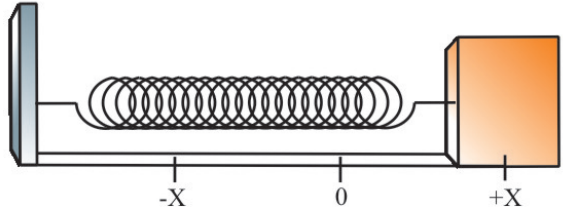

Figura 1. (a) Sistema massa-mola ideal. (b) Quando o bloco é puxado para o ponto $+X$, a energia envolvida para o movimento do bloco é transferida para o sistema como energia potencial elástica. $\mathrm{O}$ valor da energia armazenada é dada pela relação mostrada na Equação 5.

Ao soltar o bloco, a energia potencial armazenada no sistema é convertida gradualmente em cinética, conforme Equação 6:

$$
E_{C}=\frac{1}{2} m v^{2}
$$

Onde $m$ é massa e $v$ a velocidade do bloco.

Somente quando o bloco passar pela origem (e a mola volta ao seu estado natural), toda a energia potencial é convertida em energia cinética, ou seja, neste ponto a velocidade do bloco é máxima. Passando do ponto inicial, o bloco começa a perder velocidade, pois a energia cinética está sendo transferida para a mola, comprimindoa, até atingir a velocidade nula no ponto $-X$, onde somente há contribuição de energia potencial para a energia do sistema. Novamente, o bloco adquire velocidade até atingir seu valor máximo no ponto inicial e volta a estar em repouso quando se encontra em $+X$, iniciando-se novo ciclo de oscilação. Como o sistema é ideal, não apresentando perdas energéticas, a energia mecânica $\left(E_{M}\right)$, que é a soma das energias potencial (Equação 5) e cinética (Equação 6), é sempre constante, independente do tempo (Equação 7). Como exemplo ilustrativo, é mostrado na Figura 2 o ciclo de oscilação do sistema massa-mola em detalhes.

$$
\frac{d}{d t} E_{M}=0
$$

É possível deduzir uma equação diferencial que descreve o movimento oscilatório do bloco no sistema massa-mola. Da conservação da energia mecânica (Equação 7):

$$
\frac{d}{d t}\left(\frac{1}{2} m v^{2}+\frac{1}{2} k x^{2}\right)=m v \frac{d v}{d t}+k x \frac{d x}{d t}=0
$$

a:

$$
\text { Fazendo } \frac{d x}{d t}=v \text { e } \frac{d v}{d t}=\frac{d^{2} x}{d t^{2}}, \text { chega-se }
$$

$$
m \frac{d^{2} x}{d t^{2}}+k x=0
$$

A solução geral para a equação diferencial mostrada na Equação 9 é:

$$
x=X \cos (\omega t+\phi)
$$

Sendo $X$ a amplitude do movimento, $\omega$ a frequência angular de oscilação e $\phi$ a constante de fase (valor dependente do deslocamento e da velocidade do bloco em $t=0$ ). 
O sistema massa-mola é um exemplo clássico de oscilador harmônico simples linear. Realizando o cálculo da primeira e segunda derivada da Equação 10, obtém-se a relação matemática que descreve a velocidade (Equação 11) e a aceleração (Equação 12), respectivamente, do bloco oscilante no sistema em função do tempo:

$$
\frac{d}{d t} X \cos (\omega t+\phi)=v(t)=-X \omega \operatorname{sen}(\omega t+\phi)
$$

$\frac{d^{2}}{d t^{2}} X \cos (\omega t+\phi)=-X \omega^{2} \cos (\omega t+\phi)=a(t)=-\omega^{2} x(t)$

Combinando o resultado da Equação 12 com a segunda Lei de Newton, encontra-se que:

$$
F=-m \omega^{2} x
$$

Ou seja, a força restauradora da mola é proporcional ao deslocamento.
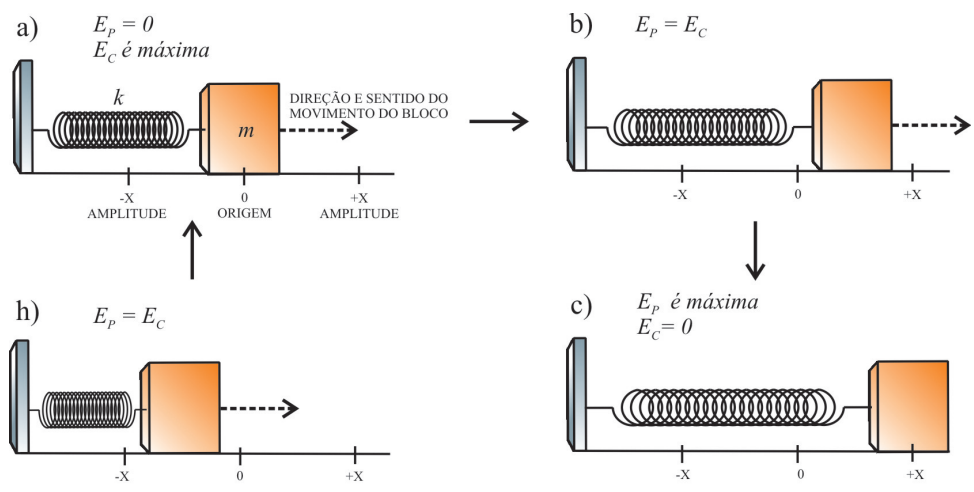

c) $E_{P}$ é máxima
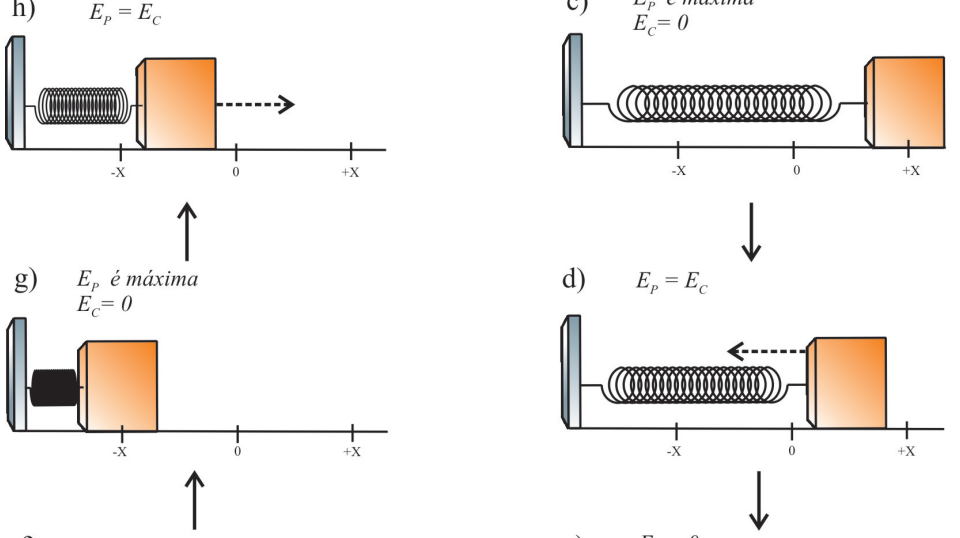

d) $\quad E_{P}=E_{C}$
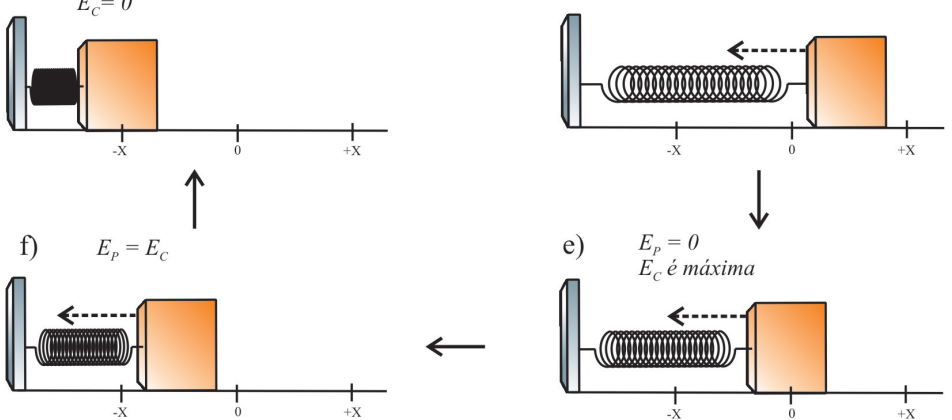

e)

e) $\quad \begin{aligned} & E_{P}=0 \\ & E_{C} \text { é máxima }\end{aligned}$

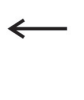

Figura 2. Mecanismo de oscilação de um sistema massa-mola após o fornecimento de energia dada pela Equação 5. A flecha "cortada" indica o sentido e direção do movimento do bloco. (a) Sistema massa-mola constituído por uma mola de constante $\mathrm{k}$ e bloco de massa $\mathrm{m}$. O bloco passa pela origem, onde a velocidade é máxima. Neste ponto, a energia cinética é máxima. (b) Quando o bloco se aproxima do ponto $+X$, a amplitude, a energia cinética é aos poucos convertida em energia potencial. (c) Quando o bloco alcança o ponto de amplitude $+X$, toda a energia cinética é convertida em potencial. Após o ponto de amplitude, em (d), o bloco começa a ganhar velocidade e alcança seu valor máximo em (e). A energia do sistema é apenas cinética em (e) e é parcialmente convertida para potencial elástica em (f). Em (g) toda a energia do sistema está armazenada na forma de energia potencial, sendo transferida parcialmente em (h) para cinética. Novamente em (a) inicia-se outro ciclo. 
Combinando a Equação 13 com a Lei de Hooke (Equação 2), encontra-se a relação que descreve a frequência angular (Equação 14) e o período de oscilação $T$ do bloco (Equação 15):

$$
\begin{aligned}
& \omega=\sqrt{\frac{k}{m}} \\
& T=2 \pi \sqrt{\frac{m}{k}}
\end{aligned}
$$

As relações matemáticas que descrevem a energia do sistema em função do tempo podem ser facilmente deduzidas combinando as Equações 5 e 10 para a Energia Potencial (Equação 16) e Equações 6 e 11 para a Energia Cinética (Equação 17):

$$
\begin{aligned}
& E_{P}=\frac{1}{2} k X^{2} \cos ^{2}(\omega t+\phi) \\
& E_{C}=\frac{1}{2} m X^{2} \omega^{2} \operatorname{sen}^{2}(\omega t+\phi)=\frac{1}{2} k X^{2} \operatorname{sen}^{2}(\omega t+\phi)
\end{aligned}
$$

Até o momento foi considerado apenas um sistema ideal, ou seja, um sistema sem a presença de forças que dissipam a energia, como o atrito entre o bloco e a superfície. Neste caso, a energia total do sistema armazenada inicialmente como energia potencial (Equação 5) é gradualmente perdida para o ambiente, sem a possibilidade de reaproveitá-la para o sistema durante os ciclos de oscilação. Estes sistemas que apresentam forças que dissipam a energia sem reaproveitamento são chamados de sistemas amortecidos. Outro exemplo de sistema oscilador amortecido é mostrado na Figura 3, que consiste em um oscilador massamola contendo uma pá imersa em um líquido, do qual exerce uma força que dificulta o movimento do bloco (amortecimento, $b$ ) quando este sobe $\mathrm{e}$ desce em seu movimento oscilatório [1].

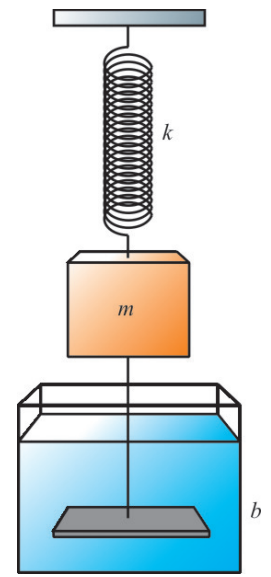

Figura 3. Oscilador massa-mola amortecido ideal. A pá imersa no líquido exerce uma força de amortecimento no sistema a cada ciclo de oscilação.

As equações que descrevem o sistema massa-mola amortecido devem levar em consideração a força de amortecimento presente no sistema $\left(F_{A}\right)$. Considerando que o sistema massa-mola amortecido mostrado na Figura 3 seja ideal e que $F_{A}$ seja proporcional em módulo à velocidade do bloco, tem-se que:

$$
F_{A}=-b v
$$

Onde $b$ é uma constante de amortecimento, que depende das características do sistema [1]. O sinal negativo indica que se opõe ao movimento do bloco.

De acordo com a segunda lei de Newton:

$$
-b v-k x=m a
$$

Substituindo $v$ por $\frac{d x}{d t}$ e $a$ por $\frac{d^{2} x}{d t^{2}}$ e rearranjando a Equação 19, encontra-se a seguinte equação diferencial

$$
m \frac{d^{2} x}{d t^{2}}+b \frac{d x}{d t}+k x=0
$$

Cuja solução é dada por

$$
x(t)=X e^{\frac{-b}{2 m} t} \cos \left(\omega^{\prime} t+\phi\right)
$$


Onde $X$ é a amplitude e $\omega$ 'é a frequência angular do oscilador amortecido.

Em termos energéticos, em um oscilador não amortecido, a energia total do sistema é dada pela Equação 5, uma relação independente do tempo. Na Equação 21, a amplitude é dada por $X e^{\frac{-b}{2 m} t}$, ou seja, a amplitude do movimento de um oscilador massa-mola amortecido depende do tempo e consequentemente, a energia também deve variar com o tempo. De fato, a energia de um sistema amortecido varia com o tempo e é dada pela Equação 22 [1].

$$
E(t) \approx \frac{1}{2} k X^{2} e^{\frac{-b}{m} t}
$$

Caso nenhuma força externa atue no sistema fornecendo energia extra, a energia decairá até zero exponencialmente. Caso contrário, se uma fonte de energia externa fornecer energia igual à perdida durante um ciclo de oscilação, o sistema permanecerá oscilando indefinidamente. Nestes casos, diz-se que o sistema é um oscilador forçado. Exemplificando, pode-se considerar como oscilador forçado o sistema massa-mola esquematizado na Figura 1 com o suporte movendo-se na horizontal em ciclos de oscilação numa frequência conhecida como $\omega_{d}[1]$. Caso esta frequência de oscilação forçada for igual à frequência de oscilação natural do sistema ( $\omega$ ou $\left.\omega^{\prime}\right)$ o sistema entrará em ressonância e, consequentemente, a amplitude de oscilação será a máxima possível.

As considerações detalhadas até o momento dizem respeito a um oscilador harmônico mecânico, embora estas deduções matemáticas também possam ser realizadas de forma análoga a um oscilador harmônico eletromagnético, como um circuito $L C$ : sistema constituído por um indutor de indutância $L$ (elemento responsável por armazenar energia magnética) e um capacitor de capacitância $C$ (elemento responsável por armazenar energia elétrica).

Ao ligar o circuito $L C$ a uma fonte de energia externa, como uma bateria (Figura 4), a energia elétrica começará a se acumular nas placas do capacitor. Neste caso, comparando com o oscilador massa-mola, a energia fornecida pela bateria ao circuito $L C$ equivale à energia fornecida ao sistema massa-mola quando o bloco é deslocado a partir de sua posição de equilíbrio. Desta forma, pode-se fazer uma analogia entre a constante $k$ da mola e a capacitância $(C)$ do capacitor.

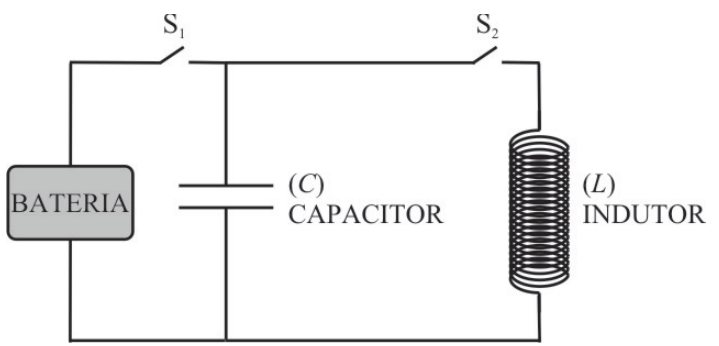

Figura 4. Circuito LC. Ao fechar a chave S1, mantendo a chave S2 aberta, o capacitor é carregado até possuir uma diferença de potencial igual a da bateria. Após o carregamento do capacitor, desligando a chave $\mathrm{S} 1$ e ligando a chave $\mathrm{S} 2$, a energia acumulada como elétrica no sistema oscilará entre elétrica e magnética.

A energia fornecida ao capacitor é igual ao trabalho que um dispositivo de fem (uma bateria) tem que executar, à custa de reações de óxido-redução, para carregar as placas do capacitor. Esta energia é armazenada como energia potencial elétrica $\left(U_{C}\right)$, dada pela relação:

$$
U_{C}=\frac{1}{2} \frac{q^{2}}{C}=\frac{1}{2} C V^{2}
$$

Onde $q$ é a carga do capacitor, $C$ sua capacitância e $V$ a diferença de potencial entre as placas. A energia para carregar o capacitor tem um limite: está inteiramente relacionada ao potencial da bateria que o capacitor está conectado, ou seja, quando a diferença de potencial entre as placas do capacitor for igual à diferença de potencial $V$ da bateria, não haverá mais carregamento das placas.

Importante notar que as Equações 5 e 23 são parecidas. De fato, as grandezas físicas presentes em ambas as equações possuem comportamento parecidos frente aos seus sistemas em particular. $\mathrm{Na}$ Equação 5, a energia potencial máxima do sistema massa-mola está relacionada, principalmente, ao quanto a mola foi esticada de sua posição de equilíbrio. No caso do circuito $L C$, a energia 
potencial máxima está relacionada à quantidade de carga que o dispositivo de fem conseguiu carregar (separar) nas placas. As grandezas $k$ e $C$ são inerentes ao elemento mola e capacitor, respectivamente, e não dependem do quanto à mola foi alongada e quantas cargas foram separadas para carregar o capacitor. Desta forma, comparando as relações matemáticas, pode-se fazer a analogia entre o capacitor e a mola (Tabela 1).

A energia armazenada nas placas do capacitor pode ser recuperada ao desligar a chave $S_{1}$ e ligar a $S_{2}$ da Figura 4. As cargas começam a fluir pelo circuito, produzindo uma corrente elétrica $i$ passando pelo indutor. Sabe-se que o indutor tem a capacidade de armazenar energia magnética $\left(U_{B}\right)$ quando uma corrente $i$ flui através do circuito. Esta energia é dada pela Equação 24:

$$
U_{B}=\frac{1}{2} L i^{2}
$$

Onde $L$ é a indutância e $i$ a corrente que passa pelo circuito.

Em um circuito ideal, sem a presença de um elemento resistivo que dissiparia a energia do sistema como térmica para o ambiente, a energia do sistema ficaria oscilando entre elétrica e magnética: quando o capacitor começa a descarregar, gera uma corrente $i$ que passa pelo circuito, fornecendo energia magnética para o indutor. Quando a energia elétrica do capacitor for nula, toda a energia do sistema estará armazenada no campo magnético do indutor. Pela Equação 24, isto ocorre quando $i$ é máximo. A partir deste ponto, $i$ começa a diminuir, significando que a quantidade de cargas responsáveis pela corrente está diminuindo. Esta queda do valor da corrente elétrica é justificada porque as cargas estão se acumulando nas placas do capacitor, transferindo a energia magnética para elétrica. Quando $i$ for nulo, toda a energia do sistema estará novamente armazenada no capacitor. As cargas começam a fluir novamente no circuito e inicia-se novo ciclo. É mostrada na Figura 5 a oscilação entre as energias elétrica e magnética no circuito $L C$ em detalhes (com capacitor de placas paralelas).

Novamente, ao realizar a analogia entre os sistemas, percebe-se o quanto eles se assemelham do ponto de vista físico. No oscilador massa-mola, após o bloco ser solto da posição $+X$, como mostrado na Figura $1 b$, toda a energia inicialmente armazenada como energia potencial elástica é transformada totalmente em cinética quando a velocidade do bloco é máxima, na posição de equilíbrio. No circuito $L C$ ocorre algo similar: quando a corrente é máxima, toda a energia elétrica do sistema é convertida em magnética. Esta analogia é evidenciada pela semelhança matemática das Equações 6 e 24. Desta forma, pode-se fazer uma analogia entre a posição do bloco e a carga do capacitor, a velocidade do bloco e a corrente do circuito e entre a massa do bloco e o indutor (Tabela 1).

As equações diferenciais que descrevem o comportamento oscilatório do circuito $L C$ também podem ser deduzidas da mesma forma que para o sistema massa-mola, já descrita anteriormente. Enquanto no sistema massa-mola a equação diferencial fornece a posição do bloco em função do tempo, no circuito $L C$ a equação diferencial dá como solução a carga do capacitor em função do tempo.

$$
q=Q \cos (\omega t+\phi)
$$

Onde $Q$ é a carga máxima no capacitor, $\omega$ é a frequência angular das oscilações eletromagnéticas e $\phi$ a constante de fase, que depende da carga contida no capacitor no tempo inicial.

Realizando o cálculo de primeira derivada da Equação 25 encontra-se a corrente em função do tempo, de forma análoga ao encontrar a velocidade do bloco no sistema massa-mola.

$$
i=\frac{d q}{d t}=-\omega Q \operatorname{sen}(\omega t+\phi)
$$

Onde o valor $\omega Q$ é a amplitude da corrente no circuito $L C$.

A frequência angular de oscilação do circuito $L C$ pode ser obtida realizando a correspon- 
dência entre as grandezas mostradas na Tabela 1 e substituindo na Equação 14. Fazendo-se estas substituições, chega-se na expressão:

$$
\omega=\frac{1}{\sqrt{L C}}
$$

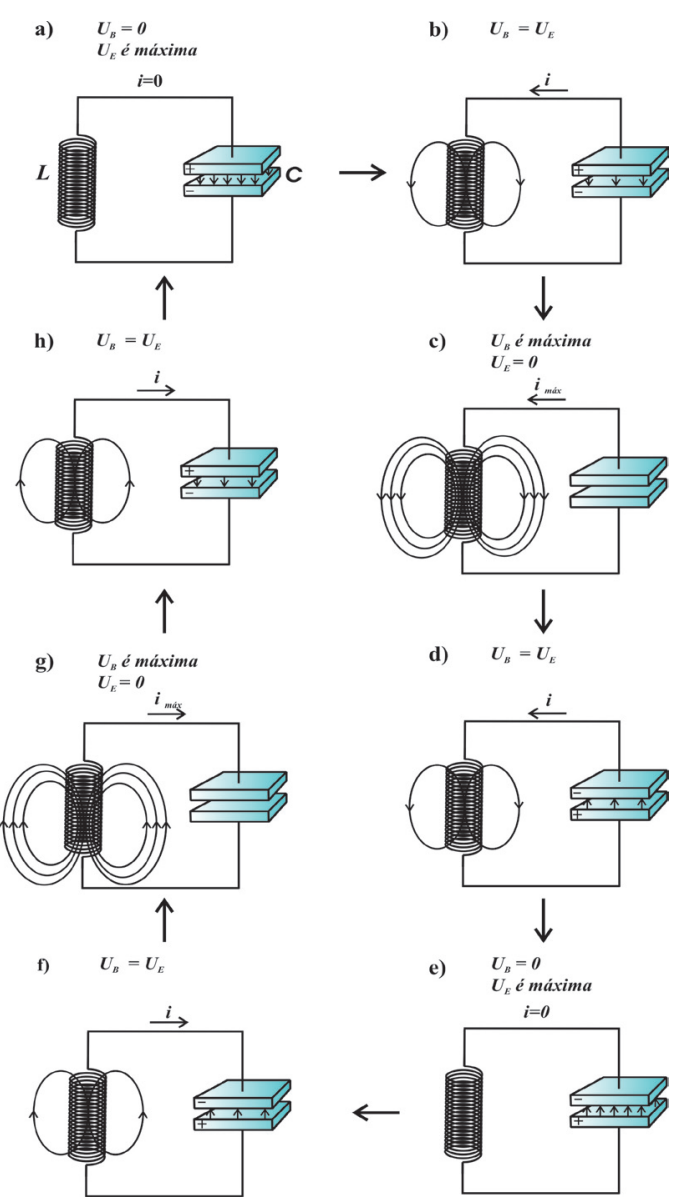

Figura 5. Mecanismo de oscilação num circuito LC, com capacitor de placas paralelas: (a) Inicialmente, toda a energia no sistema está armazenada no capacitor em forma de energia elétrica. (b) uma parte da energia inicial está armazenada no capacitor e a outra no indutor, em forma de energia magnética. (c) toda a energia armazenada inicialmente em no capacitor é transformada em energia magnética no indutor. (d) parte da energia armazenada no indutor é transferida para o capacitor (e) o sistema volta ao seu estado inicial, ou seja, toda a energia do sistema está armazenada no capacitor. Na seqüencia, os estados anteriores se repetem, formando um novo ciclo de transformação de energia. 
As equações que descrevem a oscilação em termos energéticos podem ser obtidas de forma análoga ao procedimento realizado no sistema massa-mola.

$$
\begin{aligned}
& U_{E}=\frac{q^{2}}{2 C}=\frac{Q^{2}}{2 C} \cos ^{2}(\omega t+\phi) \\
& U_{B}=\frac{L i^{2}}{2}=L \omega^{2} Q^{2} \operatorname{sen}^{2}(\omega t+\phi)=\frac{Q^{2}}{2 C} \operatorname{sen}^{2}(\omega t+\phi)
\end{aligned}
$$

Caso um elemento resistivo for introduzido no sistema, este dissipará a energia termicamente para o ambiente. Este tipo de circuito, contendo o elemento resistivo, é chamado de $R L C$.

Analogamente ao oscilador massa-mola, podem-se deduzir as equações que descrevem este comportamento. De forma geral, a energia eletromagnética total $U$ no circuito $R L C$ é dada pela soma entre as energias magnética e elétrica, uma vez que o resistor não armazena energia. Matematicamente:

$$
U=U_{B}+U_{E}=\frac{1}{2} L i^{2}+\frac{1}{2} \frac{q^{2}}{C}
$$

O resistor dissipa a energia do sistema como térmica para o ambiente na taxa de

$$
\frac{d U}{d t}=-i^{2} R
$$

Derivando a Equação 30 em relação ao tempo e combinando com a Equação 31,

$$
\frac{d U}{d t}=L i \frac{d i}{d t}+\frac{q}{C} \frac{d q}{d t}=-i R^{2}
$$

Substituindo i por $\frac{d q}{d t}$ e $\frac{d i}{d t}$ por $\frac{d^{2} q}{d t^{2}}$ chega-se na equação diferencial

$$
L \frac{d^{2} q}{d t^{2}}+R \frac{d q}{d t}+\frac{q}{C}=0
$$

$$
\text { Cuja solução é }
$$

$$
q=Q e^{\frac{-R}{2 L} t} \cos \left(\omega^{\prime} t+\phi\right)
$$

Onde

$$
\omega^{\prime}=\sqrt{\omega^{2}-\left(\frac{R}{2 L}\right)^{2}}
$$

Combinando a Equação 34 com a Equação 23, obtém-se

$$
U_{E}=\frac{q^{2}}{2 C}=Q^{2} e^{\frac{-R}{2 L} t} \cos \left(\omega^{\prime} t+\phi\right)
$$

Ou seja, a energia do sistema diminui exponencialmente com o passar do tempo, de forma análoga ao sistema massa-mola.

Com o intuito de facilitar a visualização das analogias entre os osciladores mecânico e elétrico, é apresentada na Tabela 1 um resumo da equivalência eletromecânica. 
Tabela 1. Equivalência eletromecânica

\begin{tabular}{|c|c|c|}
\hline \multicolumn{3}{|c|}{ Equivalência eletromecânica } \\
\hline Sistema massa-mola & Circuito LC & Circuito RLC \\
\hline Bloco de massa $\mathrm{m}$ & Indutor & Indutor \\
\hline Mola & Capacitor & Capacitor \\
\hline Atrito & - & Resistor \\
\hline \multicolumn{3}{|c|}{ Energia transferida para o sistema } \\
\hline Bioquímica, mecânica, etc. & Elétrica & Elétrica \\
\hline \multicolumn{3}{|c|}{ Grandezas físicas } \\
\hline $\mathrm{m}$ & $\mathrm{L}$ & $\mathrm{L}$ \\
\hline $\mathrm{k}$ & 1 & 1 \\
\hline & $\bar{C}$ & $\bar{C}$ \\
\hline $\mathrm{x}$ & $\mathrm{q}$ & $\mathrm{q}$ \\
\hline$y=\frac{d x}{x}$ & $i=\frac{d q}{}$ & $i=\frac{d q}{2}$ \\
\hline$d t$ & $d t$ & $d t$ \\
\hline Energia cinética (EC) & Energia magnética (UB) & Energia magnética (UB) \\
\hline Energia potencial elástica (EP) & Energia elétrica (UE) & Energia elétrica (UE) \\
\hline Energia térmica & - & Energia térmica \\
\hline \multicolumn{3}{|c|}{ Equações } \\
\hline$m \frac{d^{2} x}{d t^{2}}+b \frac{d x}{d t}+k x=0$ & $L \frac{d^{2} q}{d t^{2}}+\frac{q}{C}=0$ & $L \frac{d^{2} q}{d t^{2}}+R \frac{d q}{d t}+\frac{q}{C}=0$ \\
\hline$x(t)=X e^{\frac{-b}{2 m} t} \cos \left(\omega^{\prime} t+\phi\right)$ & $q=Q \cos (\omega t+\phi)$ & $q=Q e^{\frac{-R}{2 L} t} \cos \left(\omega^{\prime} t+\phi\right)$ \\
\hline$\omega^{\prime}=\sqrt{\omega^{2}-\left(\frac{b}{2 m}\right)^{2}} ; \omega=\sqrt{\frac{k}{m}}$ & $\omega=\frac{1}{\sqrt{L C}}$ & $\omega^{\prime}=\sqrt{\frac{1}{L C}-\left(\frac{R}{2 L}\right)^{2}}$ \\
\hline$E_{P}=\frac{1}{2} k x^{2} \quad$ (não-amortecido) & $U_{B}=\frac{1}{2} \frac{Q^{2}}{C} \operatorname{sen}^{2}(\omega t+\phi)$ & - \\
\hline$E_{C}=\frac{1}{2} m v^{2}$ (não-amortecido) & $U_{E}=\frac{1}{2} \frac{Q^{2}}{C} \cos ^{2}(\omega t+\phi)$ & - \\
\hline$E_{P}=\frac{1}{2} k X^{2} e^{-\frac{b}{2 m} t} \cos ^{2}\left(\omega^{\prime} t+\phi\right)$ & - & $U_{E}=\frac{1}{2} \frac{Q^{2}}{C} e^{-\frac{R}{2 L} t} \cos ^{2}\left(\omega^{\prime} t+\phi\right)$ \\
\hline$E_{C}=\frac{1}{2} k X^{2} e^{-\frac{b}{2 m} t} \operatorname{sen}^{2}\left(\omega^{\prime} t+\phi\right)$ & - & $U_{B}=\frac{1}{2} \frac{Q^{2}}{C} e^{-\frac{R}{2 L} t} \operatorname{sen}^{2}\left(\omega^{\prime} t+\phi\right)$ \\
\hline
\end{tabular}

Uma forma de permitir que o circuito $R L C$ oscile indefinidamente é alimentar este sistema com um dispositivo de fem $(E)$ alternada o que caracteriza um oscilador forçado amortecido (Figura 6). 


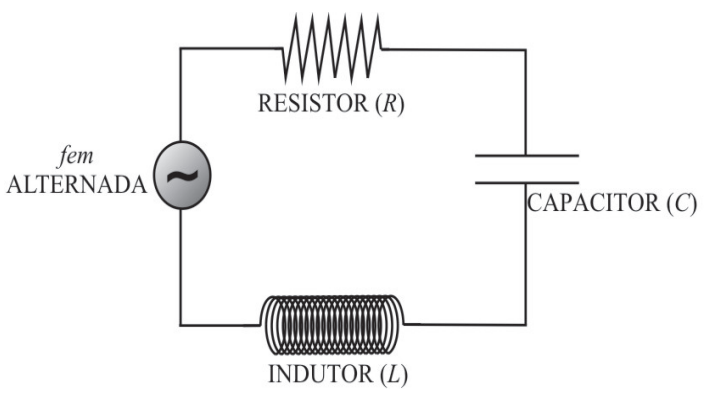

Figura 6. Circuito RLC ligado a uma fem alternada, um oscilador forçado amortecido. Similar a um sistema massa mola onde é considerado o atrito entre o bloco e a superfície.

A equação que descreve o circuito apresentado na Figura 6 é:

$$
L \frac{d^{2} q}{d t^{2}}+R \frac{d q}{d t}+\frac{1}{C} q=\mathrm{E}_{0} \operatorname{sen}\left(\omega_{d} t\right)
$$

Analogamente ao sistema massa-mola, o dispositivo de fem alternada garante ao sistema energia necessária para oscilar indefinidamente desde que a energia oferecida pela fem seja maior ou igual à energia perdida pelo resistor por ciclo.

Uma condição especial da oscilação forçada é quando a frequência angular de oscilação da fem alternada, $\omega_{d}$, é igual à frequência angular natural do circuito $R L C, \omega$ cujo fenômeno dá-se o nome de ressonância (Equação 38). Quando o sistema está em ressonância, a amplitude de carga no capacitor e corrente no circuito serão as máximas possíveis.

$$
\omega_{d}=\omega=\frac{1}{\sqrt{L C}}
$$

A ressonância é de fundamental importância quando se trabalha com técnicas eletrogravimétricas, onde é utilizada uma fonte externa de corrente alternada para promover a oscilação de um cristal de quartzo. Gravimetria é um conjunto de técnicas que possibilitam a quantificação de massa em uma determinada reação química, portanto, representa uma grande importância na Química. Deste modo, eletrogravimetria é uma forma de inferir a massa a partir de um sinal elétrico, mais especificamente por meio da frequência de ressonância do cristal, da qual se pode estabelecer a correlação eletromecânica.

Quando o cristal é forçado a oscilar alimentado por uma fonte de tensão alternada (oscilação forçada), o mesmo comporta-se como um conjunto de componentes elétricos (circuito $R L C$ ). Sendo assim, diz-se que este cristal possui um circuito equivalente, também conhecido como circuito de Butterworth-van Dike (BVD). Esta resposta do cristal de quartzo como um circuito equivalente ocorre devido ao fenômeno de piezeletricidade (que será detalhado mais adiante), um fenômeno que ocorre com certos materiais que se deformam mecanicamente quando submetidos a uma fonte de diferença de potencial. Especificamente o cristal de quartzo piezelétrico quando submetido a uma tensão de fonte de corrente alternada provoca uma oscilação mecânica no cristal de quartzo. Essa oscilação mecânica forçada é provocada eletricamente e o equivalente elétrico é um circuito $R L C$. Os elementos $R L C$ em série formam o ramo dinâmico do circuito de Butterworth-van Dike. O ramo estático é formado apenas por um capacitor $C_{0}$ (Figura 7). Este ramo é decorrência do fato de que há eletrodos metálicos sobre as faces do cristal de quartzo, um material dielétrico, em outras palavras, o conjunto eletrodo-cristal de quartzoeletrodo caracteriza um capacitor.

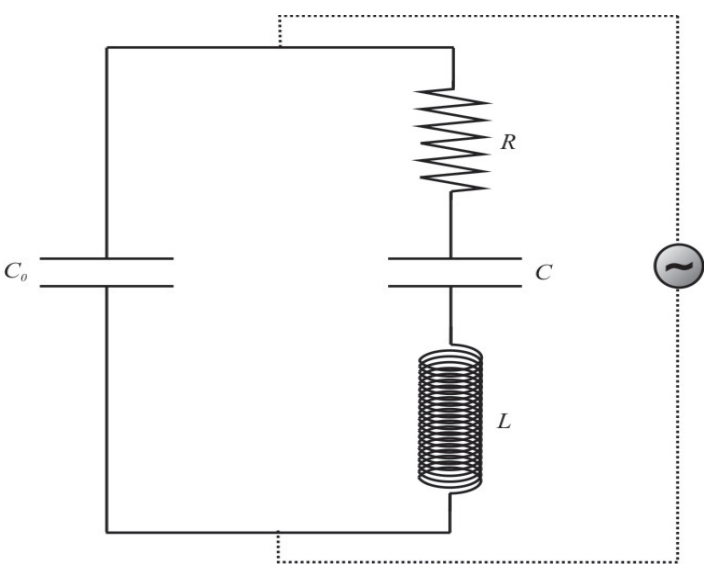

Figura 7. Circuito equivalente representando o cristal de quartzo, dividido em ramo dinâmico formado por um circuito $\boldsymbol{R} \boldsymbol{L} \boldsymbol{C}$ em série e ramo estático formado apenas por um capacitor $\boldsymbol{C}_{0}$. O circuito geral é denominado circuito de Butterworth-van Dike. O ramo dinâmico nada mais é do que uma representação elétrica equivalente para a oscilação mecânica induzida eletricamente pela fonte de tensão alternada. 
Quando a frequência da fonte for igual à frequência natural de oscilação mecânica forçada do cristal de quartzo, o sistema está em ressonância. Devido à frequência natural de oscilação mecânica precisa dos cristais de quartzo, estes são comumente utilizados como elemento de referência em circuitos que necessitam de precisão no controle da frequência.

Pode-se agora descrever melhor porque o cristal de quartzo possui uma frequência de oscilação eletromecânica. Basicamente, isso ocorre devido a uma propriedade do cristal de quartzo, a piezeletricidade. Piezeletricidade é uma propriedade que existe em certos materiais que lhes dão a capacidade de se deformarem quando submetidos a uma diferença de potencial e vice-versa (Figura 8). Desta maneira, a piezeletricidade também é a responsável pela resposta do cristal de quartzo como o circuito equivalente descrito anteriormente. A origem da piezeletricidade é a não existência de um centro de simetria no cristal, o que provoca a formação de dipolos em seu interior. Quando um cristal de quartzo é alimentado por uma corrente alternada, as cargas positivas e negativas oscilam (similar à oscilação de uma corda de violão, onde ambos os lados são fixos) e o movimento resultante no cristal é de cisalhamento de espessura (Figura $8 b$ ). A frequência da oscilação destas cargas no interior do cristal está diretamente relacionada com a sua espessura $[12,13]$. Essa relação entre a frequência e espessura do cristal é explorada em técnicas eletrogravimétricas, pois ao se adicionar algum material na superfície, seja por adsorção física ou química, faz-se com que a espessura do cristal aumente e consequentemente, sua frequência de oscilação diminui provocando mudanças nos parâmetros do circuito equivalente.

A grande vantagem de se utilizar eletrogravimetria frente a gravimetria convencional é a alta precisão conferida pela característica eletromecânica. Desta maneira, esta forma de medida de massa apresenta uma precisão superior quando comparado com outras técnicas, atingindo-se níveis de nanogramas/Hz.
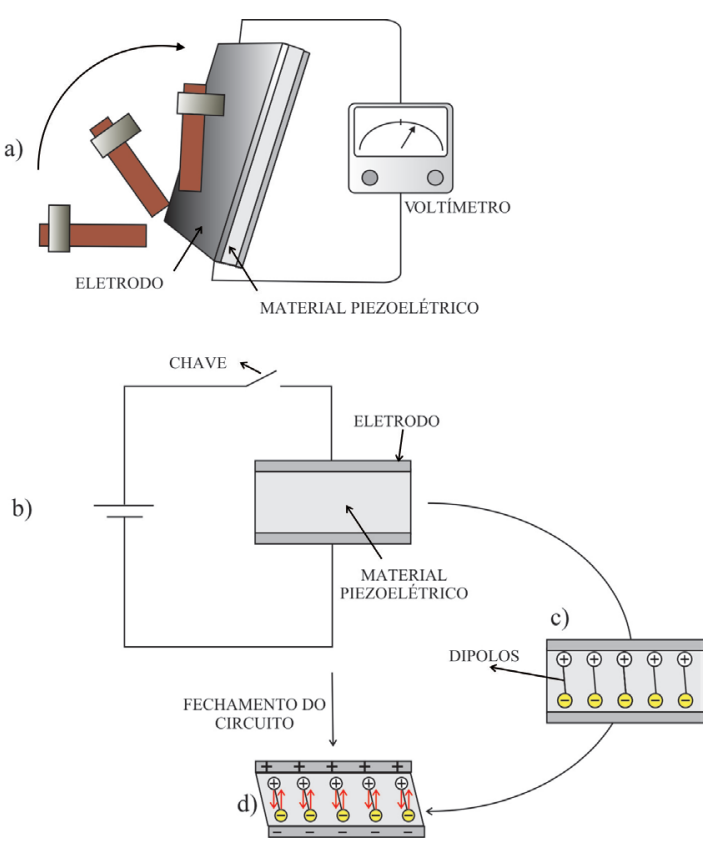

Figura 8. Fenômeno da piezeletricidade. a) Ao exercer uma força de deformação sobre o material piezelétrico, este gera uma diferença de potencial. b) Ao ligar o material piezelétrico numa fonte de diferença de potencial, como uma bateria, o material sofre uma deformação mecânica. c) Esta deformação ocorre devido a existência de dipolos no material piezelétrico. d) Quando os eletrodos são carregados, estes atraem os dipolos com carga oposta, deformando o material. Note que se a fonte de tensão é alternada, o cisalhamento também será alternando, resultando em uma oscilação forçada do cristal de quartzo, com frequência característica.

O cristal de quartzo pode ser utilizado em técnicas eletrogravimétricas de três formas distintas: a) excitação por pulso, onde é aplicado um pulso de corrente no cristal e faz-se a análise do amortecimento do cristal, b) circuito oscilador, na qual o cristal é alimentado continuamente por uma fonte de corrente alternada e c) análise da impedância ou admitância/condutância do cristal de quartzo, onde se varia a tensão do gerador de corrente alternada e analisa-se a relação tensãocorrente (impedância) ou corrente-tensão (admitância/condutância).

Usualmente, o mais utilizado é o método a), também denominado de MCQ (Microbalança à Cristal de Quartzo). Neste texto, descreveremos 
este método e também o método c), conhecido como admitância eletroacústica.

Desta forma, é importante descrevermos melhor o caso c), o qual exige ainda alguns conceitos complementares de Física. Assim, é importante recordar a resposta entre corrente e tensão para um circuito $R L C$ forçado. Para isto, vamos analisar a resposta dos componentes por partes. $\mathrm{O}$ primeiro passo é considerar um circuito simples contendo somente um resistor $R$ e a fem $(E)$ alternada (Equação 39), como já citado anteriormente (Equação 37).

$$
\mathrm{E}(t)=\mathrm{E}_{0} \operatorname{sen}\left(\omega_{d} t\right)
$$

Sendo que a corrente esperada para cada componente é da forma

$$
i=I \operatorname{sen}\left(\omega_{d} t-\phi\right)
$$

A tensão e a corrente no resistor são dados por:

$$
\begin{aligned}
& v_{R}=V_{R} \operatorname{sen}\left(\omega_{d} t\right) \\
& i_{R}=\frac{v_{R}}{R}=\frac{V_{R}}{R} \operatorname{sen}\left(\omega_{d} t\right)=I_{R} \operatorname{sen}\left(\omega_{d} t\right)
\end{aligned}
$$

Nota-se que neste circuito simples não há defasagem entre a corrente e tensão (a fase $\phi$ é zero) em um resistor. Já para um circuito contendo um capacitor e uma fem alternada, as equações são:

$$
\begin{gathered}
v_{C}=V_{C} \operatorname{sen}\left(\omega_{d} t\right) \\
i_{C}=\omega_{d} C V_{C} \cos \left(\omega_{d} t\right)=\left(\frac{V_{C}}{X_{C}}\right) \operatorname{sen}\left(\omega_{d} t+90^{\circ}\right) \text { (44) } \\
X_{C}=\frac{1}{\omega_{d} C} \text { é a reatância capacitiva. }
\end{gathered}
$$

A reatância tem a mesma dimensão da resistência $(\Omega)$.

Neste caso há uma defasagem de $-90^{\circ}$, ou seja, num circuito contendo um capacitor e uma fonte alternada, a corrente encontra-se adiantada $90^{\circ}$ em relação à tensão. Por outro lado, num circuito com uma fem alternada e um indutor, a corrente encontra-se atrasada em $90^{\circ}$ em relação à tensão (Equações 44 e 45).

$$
\begin{aligned}
& v_{L}=V_{L} \operatorname{sen}\left(\omega_{d} t\right) \\
& i_{L}=\left(-\frac{V_{L}}{\omega_{d} L}\right) \cos \left(\omega_{d} t\right)=\left(\frac{V_{L}}{X_{L}}\right) \operatorname{sen}\left(\omega_{d} t-90^{\circ}\right)
\end{aligned}
$$

Sendo $X_{L}=\omega_{d} L$ a reatância indutiva.

Após a análise dos componentes em separado com uma fonte alternada, é interessante analisar a resposta de um circuito $R L C$ em série com uma fonte alternada, ou seja, analisar a resposta de um oscilador forçado amortecido e consequentemente um circuito parecido com o circuito equivalente do cristal de quartzo.

Utilizando as leis das malhas na Figura 6, encontra-se:

$$
\mathrm{E}=v_{R}+v_{C}+v_{L}
$$

A forma mais simples de resolver a Equação 44 é utilizando um diagrama de fasores ou vetores de rotação que são vetores bidimensionais que giram no plano, neste caso, este plano é formado pelos eixos denominados como amplitude (ordenada) e fase (abscissa). Pode-se encontrar a relação resultante considerando um instante $t$ qualquer. Neste instante, temos a amplitude

do potencial $\left(V_{R}\right)$ com uma fase $\omega_{d} t+\phi$ (Figura 9(a)). Para outros elementos há uma defasagem de $\pm 90^{\circ}$ em relação ao potencial no resistor, como visto anteriormente, a tensão no capacitor encontra-se atrasada em relação à corrente e no indutor a tensão está adiantada (Figura 9(b)). Já a tensão da fem $(E)$ tem fase zero em qualquer instante $t$ (Figura 9(c)). Na Figura 9(d) está representada a soma dos fasores, onde nota-se que a soma dos vetores $V_{R}$ e $\mathrm{V}_{\mathrm{L}}-\mathrm{V}_{\mathrm{C}}$ resulta em $E_{0}$. 


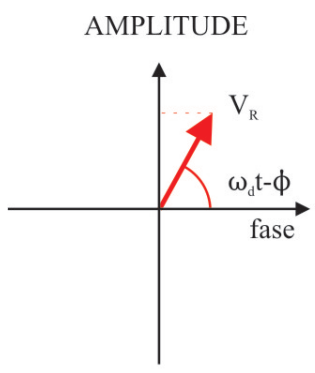

(a)

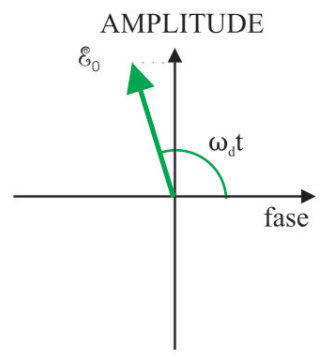

(c)

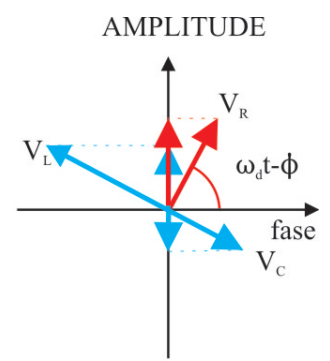

(b)

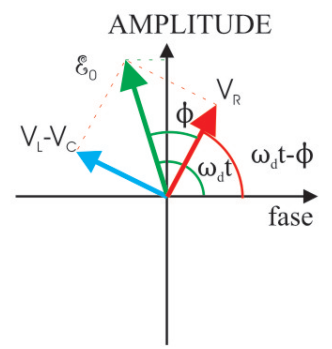

(d)
Figura 9. Diagrama de fasores para um circuito RLC. Em (a) a amplitude VR num dado instante t. (b) A soma dos fasores, com VL adiantado em $90^{\circ} \mathrm{e}$ VC atrasado em $90^{\circ}$ em relação ao fasor VR. (c) $\mathrm{O}$ fasor E0, cuja fase é zero e em (d) a soma dos fasores representados em (b) resulta em E0.

Pela soma vetorial nota-se que o vetor $V_{L} \mathrm{e}$ $V_{C}$ possuem a mesma direção, mas sentidos opostos, logo a resultante desta soma vetorial é $V_{L}-V_{C}$. Desta forma, a soma vetorial entre $V_{R}$ e $V_{L}-V_{C}$ é dada por:

$$
\mathrm{E}_{0}^{2}=V_{R}^{2}+\left(V_{L}-V_{C}\right)^{2}
$$
obtém-se

Substituindo as amplitudes dos potenciais,

$$
\mathrm{E}_{0}^{2}=(I R)^{2}+\left(I X_{L}-I X_{C}\right)^{2}
$$

Desta forma, a corrente é dada por

$$
I=\frac{\mathrm{E}_{0}}{\sqrt{R^{2}+\left(X_{L}-X_{C}\right)^{2}}}
$$

Onde o termo $\sqrt{R^{2}+\left(X_{L}-X_{C}\right)^{2}}$ é conhecido como impedância e o inverso desta relação é a admitância.

obtém-se

Substituindo as reatâncias na Equação 47,

$$
I=\frac{\mathrm{E}_{0}}{\sqrt{R^{2}+\left(\omega_{d} L-\frac{1}{\omega_{d} C}\right)^{2}}}
$$

Analisando a Equação 48 nota-se que a corrente máxima ocorre quando o termo $\underset{\text { que }}{\omega_{d} L-\frac{1}{\omega_{d} C}=0 . \text { Nestas condições, encontra-se }}$ $\omega_{d}=\frac{1}{\sqrt{L C}}$

$\mathrm{Ou}$ seja, o pico de corrente ocorre justamente na frequência de ressonância, pois

$\frac{1}{\sqrt{L C}}$ natural de um circuito $R L C$. O gráfico da corrente em função da frequência da fonte alternada é apresentado na Figura 10.

No caso prático, sempre que houver uma adsorção de massa sobre o cristal de quartzo, haverá uma variação de frequência, porque $\Delta m$ causará uma variação em $\Delta L$, conforme nos indica o equivalente eletromecânico (ver Tabela 1). A variação de $\Delta L$ induz uma diminuição da frequência de ressonância de acordo com a Eq. (49). Desta maneira, nota-se que uma variação positiva de massa causa uma variação negativa na frequência de ressonância. A equação que define esta relação é conhecida como equação de Sauerbrey e é representada abaixo:

$$
\Delta f=-C_{f} \Delta m
$$

Nesta equação, $C_{f}$ é uma constante que depende das características físicas do cristal de quart- 
zo (módulo de cisalhamento, densidade, etc.). Esta equação é quantitativamente válida com precisão para massas rígidas e quando a $\Delta m$ é menor que $10 \%$. Além disso, a Equação 50 define e fundamenta as técnicas eletrogravimétricas conhecidas como Microbalança à Cristal de Quartzo (QCM).

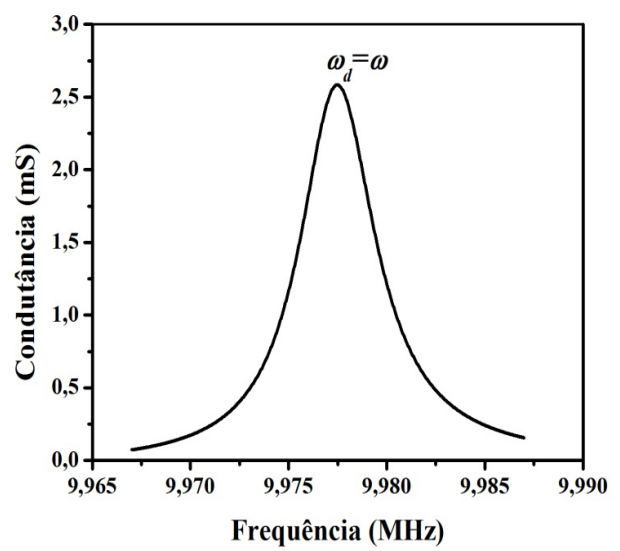

Figura 10. Gráfico da corrente (note que a corrente é proporcional a condutância) em função da frequência da fonte de corrente alternada para um circuito $R L C$.

Na próxima seção será descrito um experimento que pode ser facilmente reproduzido em laboratório, mesmo didático, o qual exemplifica os conceitos expostos neste texto e basicamente sumariza a aplicação do equivalente eletromecânico na área de química e ou/ biotecnologia.

\section{Materiais e Métodos}

Nesta seção, são descritos os materiais e métodos que podem ser empregados no experimento de estudo do equivalente eletromecânico em cursos de pós-graduação em biotecnologia ou mesmo nos cursos de graduação em química ou biologia. Este experimento pode ser indicado como um experimento conjunto para os cursos de bioquímica e física e/ou biofísica para um curso de farmácia, por exemplo.

Propõe-se utilizar cristais de quartzo de corte AT com frequência fundamental de $10 \mathrm{MHz}$, diâmetro de 16 mm, e $290 \mu \mathrm{m}$ de espessura, con- tendo eletrodos de ouro concêntricos de $5 \mathrm{~mm}$ de diâmetro em ambos os lados. Para promover a oscilação do cristal de quartzo os eletrodos de ouro foram presos mecanicamente em contatos metálicos. O conjunto suporte com contato e cristal de quartzo deve ser inseridos em uma célula de medida confeccionada em TEFLON ${ }^{\circledR}$, sendo utilizados anéis de silicone ("O-Rings") em ambos os lados para a vedação. A Figura 10 mostra o esquema de montagem da célula.

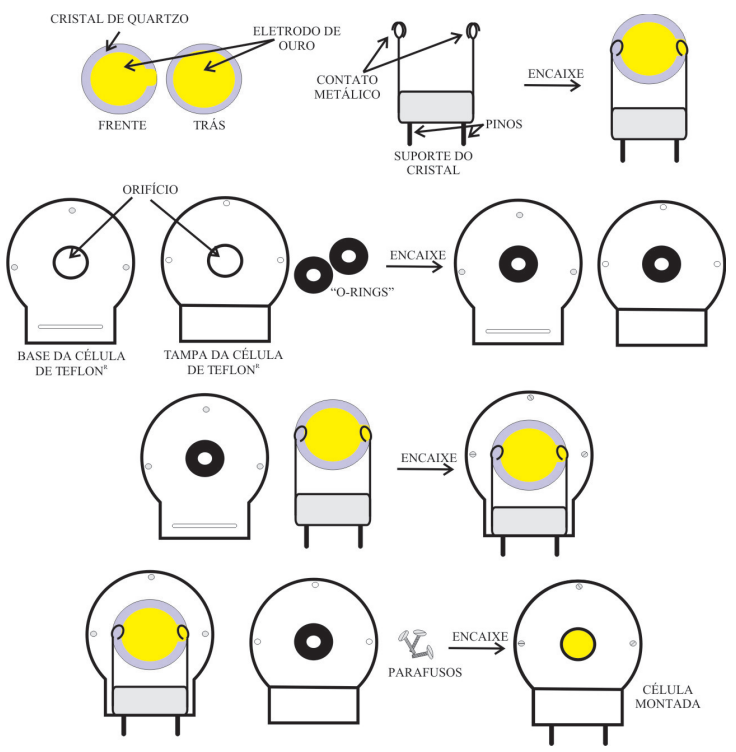

Figura 11. Esquema de montagem da célula. Depois de lavado, o cristal é inserido nos contatos metálicos. O conjunto, cristal-contatos é inserido numa célula de TEFLON® entre O-rings e depois a célula e fechada e ligado ao impedancímetro.

Neste caso, optou-se pela realização de medidas de admitância/condutância eletroacústica utilizando um analisador de resposta em frequência de precisão da Agilent modelo 4294 A, com capacidade de varredura em frequência de $40 \mathrm{~Hz}$ a $110 \mathrm{MHz}$ e precisão na impedância de $\pm 0,8 \%$ e $1 \mathrm{mHz}$ para a frequência. Este é um equipamento sofisticado e de alto custo para laboratórios didáticos e foi utilizado somente com a finalidade de detalhar o conceito de equivalente eletromecânico discutido neste texto. No entanto, o experimento também pode ser realizado utilizando-se somente um circuito oscilador (custo baixo, em torno de US\$ 100,00) e um frequencímetro, equipamento 
comumente encontrado em laboratórios didáticos de física.

$\mathrm{O}$ analisador de resposta em frequência para os estudos realizados pode ser ajustado da seguinte maneira: medida de $G-B$ (condutância e susceptância que são as partes real e imaginária da admitância, respectivamente); 801 pontos de aquisição que é justamente o máximo de pontos fornecidos pelo equipamento para obter uma precisão maior nas medidas; calibrações para subtrair a impedância/admitância do sistema (contato e cabos) calculadas pelo próprio equipamento. Após esses ajustes mede-se a admitância/condutância do cristal inserido no contato metálico e o conjunto inserido na célula para encontrar a frequência de oscilação do cristal com o objetivo de escolher o melhor intervalo de frequência a ser estudado. Além disso, varia-se a frequência entre $-10 \mathrm{kHz}$ e $+10 \mathrm{kHz}$ em relação à frequência de ressonância do cristal de quartzo. A condutância é proporcional a corrente indicada e exemplificada na Figura 10.

\section{Detalhes do Experimento}

Com o objetivo de demonstrar um experimento que ilustre a analogia eletromecânica relacionando conceitos físicos e químicos, propõe-se o estudo da formação de um filme automontado. Filmes automontados, conhecidos como Self Assembled Monolayer (SAM), são camadas autoorganizadas de substâncias que possuem grande afinidade por uma superfície metálica, como a forte interação entre o átomo de enxofre de tióis (-SH), sulfeto e dissulfeto pelo ouro $[10,11,14$, 15]. O estudo da formação destas camadas é muito importante porque é chave para a obtenção de biossensores: são nestas estruturas que os biossensores são construídos.

Para o exemplo deste trabalho foi utilizada a substância cistamina, um dissulfeto contendo grupos amina em ambos os lados da molécula (Figura 12). Encontra-se na literatura que dissulfetos ligam-se ao ouro rompendo as ligações S-S [16].

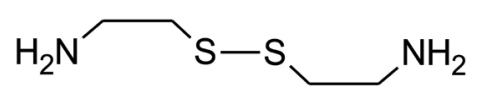

Figura 12. Representação esquemática da molécula de cistamina, o dissulfeto utilizado para detecção de massa na superfície do ouro, devido ao fato que a mesma se ligará covalentemente a superfície do ouro.
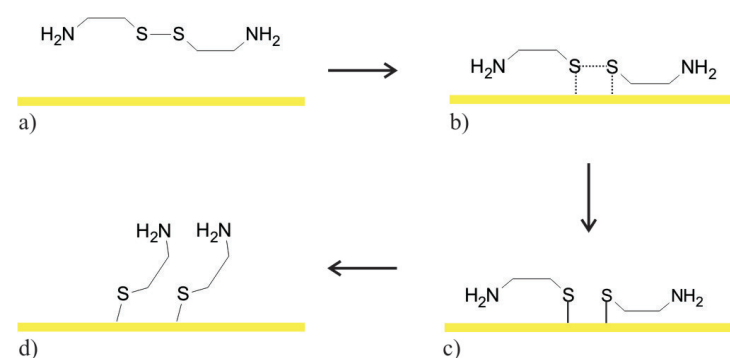

b)

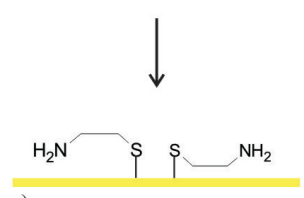

c)

Figura 13. Esquema hipotético da formação da ligação entre cistamina e ouro. a) Aproximação do cistamina na superfície de ouro. b) Quando os átomos de enxofre e ouro estão próximos sufuciente, ocorre o rompimento da ligação $\mathrm{S}-\mathrm{S}$ ao mesmo tempo em que duas ligações $\mathrm{Au}-\mathrm{S}$ se formam. Em c) ocorre a formação da ligação $\mathrm{Au}-\mathrm{S}$ e d) as moléculas se autoorganizam.

É importante, antes da adição da cistamina na célula contendo o cristal de quartzo, esperar a estabilização do cristal em água destilada antes de medir a admitância/condutância deste sistema (Figura 14). Então, a solução de cistamina (concentração de $0,1 \mathrm{M}$, preparada em água destilada) é adicionada (Figura 15) de modo que a concentração deste dissulfeto na célula seja de $17,5 \mathrm{mmol} / \mathrm{L}$ e espera-se cerca de 30 minutos para a formação da monocamada. Após este tempo o cristal pode ser lavado com água e a admitância pode ser novamente medida (Figura 14). 


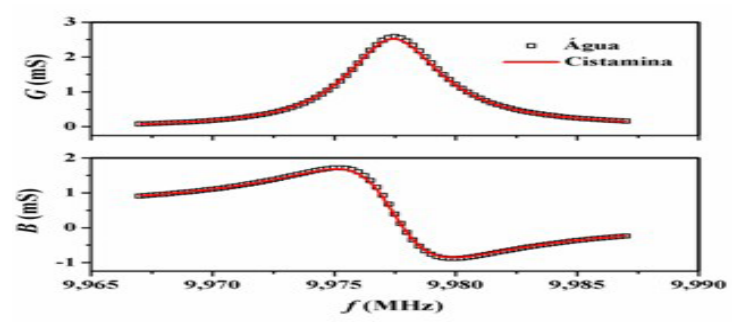

Figura 14. Curvas de admitância para a célula contendo apenas água e após a formação da monocamada de cistamina.

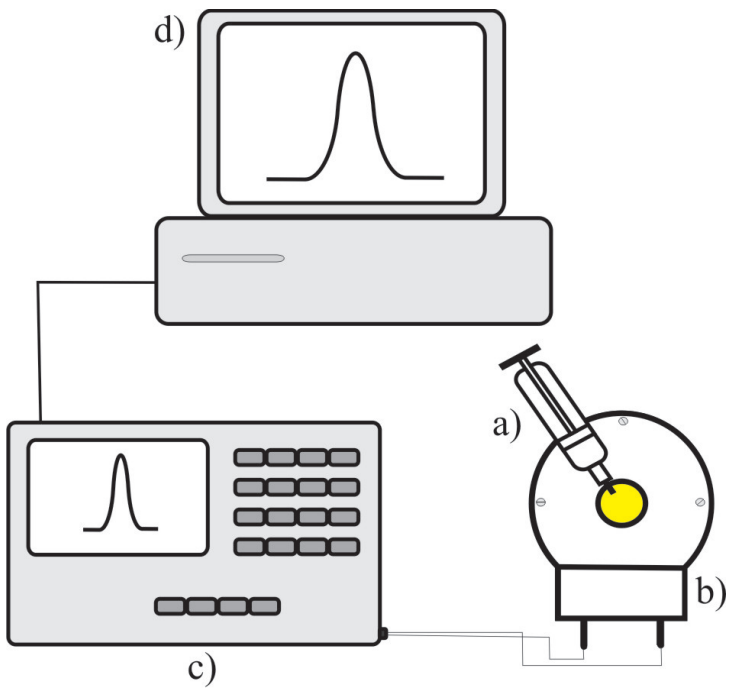

Figura 15. Esquema da imobilização da cistamina em ouro. a) Seringa contendo solução de cistamina. b) Célula contendo água destilada. c) Impedancímetro e d) computador.

As curvas de admitância/condutância da Figura 14 foram submetidas a um ajuste utilizando o algoritmo de Levenberg-Marquardt. Com este ajuste pode-se os valores e parâmetros do circuito equivalente. Estes parâmetros são mostrados na Tabela 1. Note que este procedimento foi realizado aqui para exemplificar e deixar aqui dados de referência para um experimento em laboratório didático, o qual poderia ser realizado simplesmente observando-se o deslocamento do valor de frequência de ressonância do cristal, medida por um frequencímetro comum.

Tabela 2. Parâmetros do circuito equivalente para a célula contendo água e cistamina.

\begin{tabular}{c|ccccc}
\cline { 2 - 5 } & $R(\Omega)$ & $L(\mathrm{mH})$ & $C(\mathrm{fF})$ & $C_{0}(\mathrm{pF})$ & $f(\mathrm{~Hz})$ \\
\hline Água & 385 & 13,4182 & 18,96262 & 6,070464 & 9977536 \\
Cistamina & 395 & 13,4196 & 18,96089 & 6,143297 & 9977495 \\
Diferença & 10 & 0,0014 & $-0,00173$ & 0,072833 & -41 \\
\hline
\end{tabular}

De acordo com a analogia eletromecânica, pode-se notar que houve um aumento na massa e um decréscimo na constante de mola quando estas alterações são comparadas com um oscilador mecânico (Tabela 3).

Tabela 3. Parâmetros de um oscilador mecânico obtidos ao realizar a analogia eletromecânica com os valores mostrados na Tabela 2.

\begin{tabular}{c|ccccc}
\cline { 2 - 5 } & $b(\mathrm{~kg} / \mathrm{s})$ & $m(\mathrm{~g})$ & $k\left(10^{13} \mathrm{~N} / \mathrm{m}\right)$ & $k_{0}\left(10^{11} \mathrm{~N} / \mathrm{m}\right)$ & $f(\mathrm{~Hz})$ \\
\hline Água & 385 & 13,4182 & 5,27353 & 1,647327 & 9977536 \\
Cistamina & 395 & 13,4196 & 5,27179 & 1,627790 & 9977495 \\
Diferença & 10 & 0,0014 & $-0,00174$ & $-0,01953$ & -41 \\
\hline
\end{tabular}


De acordo com os dados apresentados na Tabela 2, a diferença entre a indutância do circuito equivalente contendo cistamina (diluído em água) e apenas água foi de $14 \mu \mathrm{H}$. Aplicando a analogia eletromecânica (Tabela 3 ) verifica-se que esta variação equivale a $1,4 \mathrm{mg}$.

$\mathrm{O}$ esquema mostrado na Figura 16 ilustra as variações dos parâmetros $\mathrm{R}, \mathrm{L}$ e $\mathrm{C}$ devido à formação da monocamada, conforme Tabela 2. É importante ressaltar que o experimento realizado aqui ilustra a aplicação dos conceitos da analogia eletromecânica na área específica de bioquímica ou química, dependendo da abordagem que o professor em sala de aula queira dar para seus alunos. A Equação 50, conforme comentado, é quantita- tivamente válida para $\Delta m$ menores que $10 \%$ e massas rígidas, o que não é caso do presente experimento. Porém, é importante notar, que mesmo nos casos em que tal condição não é obedecida, que é o caso também do experimento presente, a relação é sempre válida do ponto de vista qualitativo. Sempre que houver uma ligação química na camada ativa (que pode ser arquitetada como se desejar) haverá uma resposta elétrica, i.e. variação da frequência de oscilação. Esta informação é importante, porque com isso pode-se projetar biossensores, ou seja, detecção de bioquímica ou biomolecular a partir de um sinal elétrico. É assim que são desenhados os sensores biológicos baseados nos conceitos eletrogravimétricos.

a)

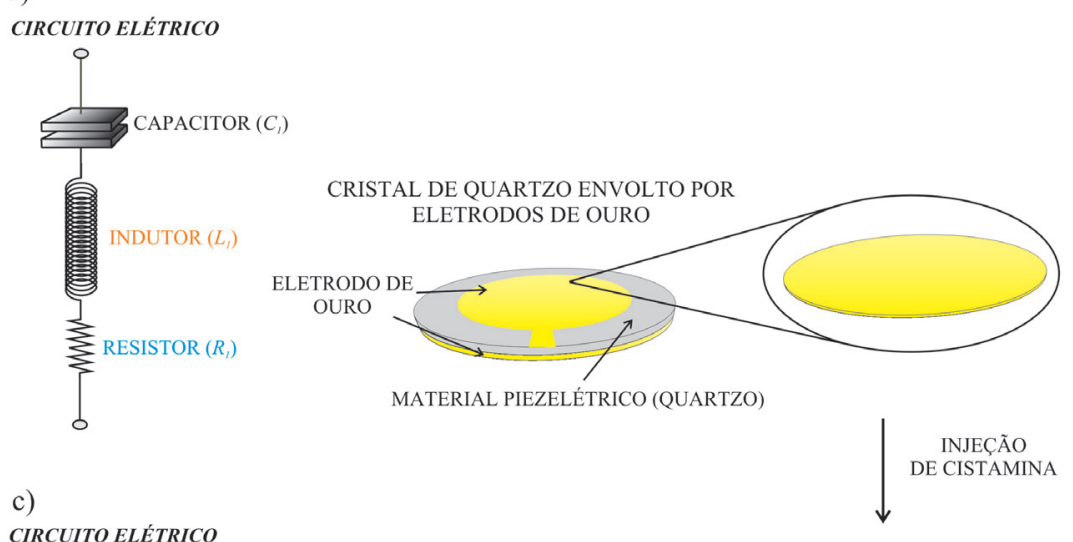

CIRCUITO ELÉTRICO

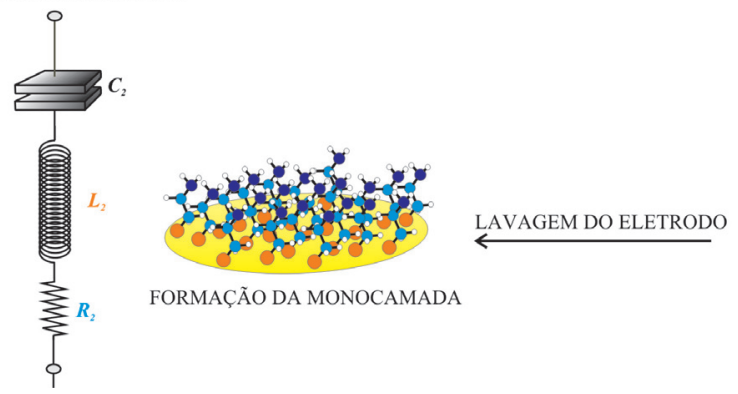

b)

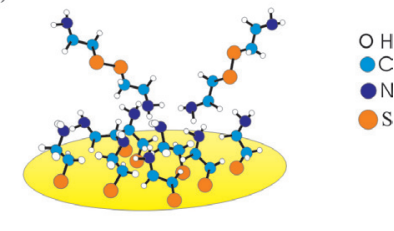

QUEBRA DA LIGAÇÃO S-S DA CISTAMINA E FORMAÇÃO DA LIGAÇÃO DO TIPO Au-S

Figura 16. Mecanismo proposto para a formação da monocamada de cistamina em ouro considerando variações dos parâmetros R, L e C. As moléculas de solvente (água) não foram desenhadas para clareza do desenho. (a) A oscilação forcada de um cristal de quartzo pizelétrico em uma frequência f pode ser comparada ao circuito de Butterworth-van Dike. (b) A cistamina começa a se ligar no ouro, através da quebra da ligação $\mathrm{S}-\mathrm{S}$. (c) Após a lavagem do eletrodo, a variação de massa sobre a superfície do quartzo está relacionada com uma alteração dos parâmetros C1, L1 e R1 para C2, L2 e R2. 
A importância das técnicas eletrogravimétricas está em sua alta precisão, pois pequenas variações de massa depositadas sobre o cristal de quartzo podem ser detectadas.

Finalmente, é importante frisar que a variação dos demais parâmetros além do $L$ no experimento exemplificador dos conceitos físicos abordados no texto é devido aos fatores já discutidos de massa não rígida. Neste caso, poder-se-ia discutir conceitos de viscoelasticidade, etc., caso o experimento fosse direcionado diretamente para alunos de física, onde uma abordagem mais profunda poderia ser dada.

\section{Conclusões}

O experimento do equivalente eletromecânico proposto aqui, além de ser interdisciplinar, pois pode ser trabalhado com cursos de Física, Química e Biologia, fornece dados relevantes sobre o material que está sendo estudado devido à exploração da analogia entre os osciladores mecânico e elétrico para detecção precisa de massa. Além disso, o experimento pode ser realizado em diversas abordagens dependendo do nível de conhecimento que se queira ministrar aos alunos, ou seja, é possível aplicar tanto uma abordagem superficial quanto uma mais profunda, desde o ponto de vista físico (caso o curso seja direcionado a alunos do curso de física) como para as outras disciplinas.

Resumo: De forma geral, os cursos de física clássica oferecidos nas universidades carecem de exemplos de aplicações nas áreas de química e biologia, o que por vezes desmotivam os alunos de graduação destas áreas a estudarem os conceitos físicos desenvolvidos em sala de aula. Neste texto, a analogia entre os osciladores elétrico e mecânico é explorada visando possívies aplicações em química e biologia, mostrando-se de grande valia devido ao seu uso em técnicas de medição de variação de massa com alta precisão, tanto de forma direta como indireta. Estas técnicas são conhecidas como técnicas eletrogravimétricas e são de especial importância em aplicações que envolvem biossensores. Desta forma, o texto explora o estudo da analogia eletromecânica de forma interdisciplinar envolvendo as áreas de física, química e biologia. Baseado nessa analogia é proposto um experimento que permite a sua aplicação em diferentes níveis conceituais dessas disciplinas, tanto em abordagem básica como mais profunda.

Palavras-chave: Oscilador massa-mola; oscilador RLC; equivalência eletromecânica; oscilador piezoelétrico; eletrogravimetria.

\section{REFERÊNCIAS}

[1] D. Halliday, R. Resnick, J. Walker, Fundamentos de Física, Livros Técnicos e Científicos, Rio de Janeiro, 6. ed., 2002, v. 2.

[2] H. M. Nussenzveig, Curso de Física Básica, Edgar Blucher, São Paulo, 3. ed., 1997, v. 2.

[3] P. A. Tipler, G. Mosca, Física para cientistas e engenheiros, Livros Técnicos e Científicos, Rio de Janeiro, 5. ed., 2006, v. 1.

[4] J. B. Marion, Classical Dynamics of Particles and Systems, Academic Press, New York, 2nd edn., 1970,

[5] L. D. Landau, E. M. Lifshitz, Course of Theoretical Physics, Pergamon Press, New York, 3rd edn., 1988, v. 1.

[6] R. W. Fox, A. T. Mcdonald, Introdução à Mecânica dos Fluidos, Guanabara Dois, Rio de Janeiro, 2. ed., 1981,

[7] D. Tomasi, E. C. Caparelli, Rev. Bras. Ens. Fis. 23(2) (2001) 171.
[8] D. Halliday, R. Resnick, J. Walker, Fundamentos de Física, Livros Téenicos e Científicos, Rio de Janeiro, 6. ed., 2002, v. 3.

[9] Y. S. Fung, Y. Y. Wong, Anal. Chem. 73(21) (2001) 5302. [10] J. C. Love, L. A. Estroff, J. K. Kriebel, R. G. Nuzzo, G. M. Whitesides, Chem. Rev. 105(4) (2005) 1103.

[11] T. Wink, S. J. Vanzuilen, A. Bult, W. P. Vanbennekom, Analyst 122(4) (1997) R43.

[12] Hewlett-Packard Company. HP Application Note 200-2: fundamentals of quartz oscillators, 1997, $28 \mathrm{p}$.

[13] D. A. Buttry, M. D. Ward, Chem. Rev. 92(6) (1992) 1355.

[14] C. D. Bain, H. A. Biebuyck, G. M. Whitesides, Langmuir 5(3) (1989) 723.

[15] C. D. Bain, E. B. Troughton, Y. T. Tao, J. Evall, G. M. Whitesides, R. G. Nuzzo, J. Am. Chem. Soc. 111(1) (1989) 321.

[16] A. Ulman, Chem. Rev. 96(4) (1996) 1553. 